\title{
Investigation and Research on the Artistic Characteristics of Tea-Leaf Picking Opera in Northern Guangdong and Its Current Situation*
}

\author{
Guangtao Cao \\ School of Foreign Languages \\ Shaoguan University \\ Shaoguan, China 512005
}

\author{
Siyu Xue \\ School of Foreign Languages \\ Shaoguan University \\ Shaoguan, China 512005
}

\begin{abstract}
As a national intangible culture heritage, the Hakka Tea-leaf Picking Opera in northern Guangdong has formed an artistic feature of "Sanzi". Through the investigation to some Tea-leaf Picking Operas in Nanxiong, Wongyuan etc. of Shaoguan City, it is easy to find that with remarkable achievements, Hakka Tea-leaf Picking Opera still faces the crisis of lack of talents, shrinking market, insufficient government support and social attention. According to this, the importance strategy of the system is put forward to be used as reference by the relevant management department.
\end{abstract}

Keywords-Tea-leaf Picking Opera; current existence; investigation and research

\section{INTRODUCTION}

The climate in northern Guangdong is mainly tropical and subtropical monsoon climate with high temperature and rainy summer. The terrain is mainly mountains and hilly, which is very suitable for the growth of tea trees. In the collective work, in order to adjust the physical strength and create a production atmosphere, tea famers will sing folk Tea-leaf Picking songs randomly to reduce the pressure of work, which were gradually formed as Tea-leaf Picking Opera in northern Guangdong after years of development, and was spread to Shaoguan, Meizhou and Qingyuan etc.

Tea-leaf Picking Opera in northern Guangdong is one of the earliest Hakka Tea-leaf Picking Operas in China, the performing art featured by "Sanzi" embodies the production and life interests of the Hakka people, which is very popular within publics in Hakka areas and is an important part of Hakka culture of Lingnan. In this paper, the artistic characteristics, existence and inheritance of "Sanzi" of Hakka Tea-leaf Picking Opera in northern Guangdong will be explored and analyzed.

*Fund: 1. Achievements of the 2019 college students' innovation and entrepreneurship training project "Investigation and Research on Tea-leaf Picking Opera in northern Guangdong" (S201910576044). 2. Shaoguan social science planning project in 2019 "study on the translation of classical opera into English based on functional approaches - a brief discussion on Liao Yan's plays and their translation" (Z2019007).

\section{Performance StYle OF "SAnZI" ART}

Hakka Tea-leaf Picking Opera in northern Guangdong has developed from local opera, now it has profound history and culture and rich artistic expression. The highest level of drama aesthetics is not the beauty of realism, but the beauty of artistic conception. However, the beauty of artistic is not absolute. In the virtual space of the stage, "the virtual" is conditional. For example, horses can be virtual but whips cannot be. Ships can be virtual, oars cannot be. Wine can be virtual, cups cannot be. Compared with other sister operas, Tea-leaf Picking Opera has much more artistic conception, and this unique art has been concluded by predecessor as "Sanzi" art. The so-called "Sanzi", that is "Buzi", "Xiuzi", "Shanzi", is the highly development of formal beauty and the most flexible use of virtual space, "transfer the reality to virtuality" and "transfer the specification to abstraction". In order to realize the easy dissemination, teaching, understanding and remembering, the senior artists have compiled the "jargon" of Sanzi" art into the "Sanzi" proverb after carefully refining.

\section{A. "Buzi" Proverb}

The full name of "Buzi" of Tea-leaf Picking Opera is "Aizibu". Aizibu can be divided as "Gaozhuangbu", "Zhongzhuangbu", and "Dizhuangbu".

1) Gaozhuang proverb: Stepping the Gaozhuang with high gait, looking straight ahead, bending knee like hook, straightening the waist like a gun, the spoken parts should be displayed with cross step, the cross means the way to all sides, happiness is displayed with three-step running, and the drunk gait should be stumble along.

2) Zhongzhuang proverb: Middle gait is not low or high, relaxing the shoulders and waist, the actor should perform like the large road is rough and jump when come across the small road, step on to the even road freely, and tell stories with slow gaits and tenderness, cross the bridge with horizontal steps, lift the hips when carrying items.

3) Dizhuang proverb: Horsing riding steps is used in Dizhuang, the body should be much shorter when climbing, 
actors should boggle the legs in darkness, display the catlike gait as stepping on the cotton, display the duck-like gait by looking around, perform the upset with mouse-like step, and perform the peaceful mind with rabbit-like step, squat down like a Buddha, constrict the waist and abdomen, and sink suction and make the waist hard, tight the legs.

All of "Aizibu", whether it is "Gaozhuang", "Zhongzhuang" or "Dizhuang", should take advantage of using the breath. The Bufa of "Aizibu" is connect with Shenfa, using the breath, relaxing the shoulders, turning around by legs, turning over by waist, actors can be drunk but the horse cannot, actors can be dizzy but the ship cannot, it is said in the proverb: standing like the legs of a horse, swinging like a dog's tail, swimming like a snake swimming in river, walking lightly as a ghost in night.

\section{B. "Xiuzi" Proverb}

The sleeves of the role of Chou in Tea-leaf Picking Opera hav distinctive feature, compared with its sister operas, the "Xiuzi" Kongfu of Tea-leaf Picking Opera is much more offbeat. The short "Xiuzi" in Tea-leaf Picking Opera is like "having sleeves is like having no sleeves", the long one can down to the ground. The actors (Male Chou) of Tea-leaf Picking Opera perform with a single long sleeve, which is called as "Single Shuixiu" by artists There dozens of performing styles of "Single Shuixiu" like "Throwing", "Withdrawing", "Grabing", "Swing", "Turning", "Putting" etc. The prima role of Chou depends on "Sing Shuixiu" to describe the figures, which has played a great artistic effect in shaping images. The outstanding performance of "Single Shuixiu" has deepened the comedy color of Tea-leaf Picking Opera in the funny, humorous and fantastic aspects, is the important support of exaggerated body and feeling, and is the essence of Tea-leaf Picking Opera.

The requirements of "Single Shuixiu" produced by predecessor: moving and keeping static with certain degree, and showing Kongfu with proper way. The quick action should be clean, while the slow action should be soft with manly. It should be quick but not brisk, be agile but not frivolous, and be stable but not stiff, be extending but not unrestrained. That is the slow action should be tight, and the tense rhythm should be relaxed, it is said in the proverb:

- The sleeves Kongfu of Chou in Tea-leaf Picking Opera ranks number one in the operas field with one short sleeve and one long sleeve. The short sleeve is performed like having no sleeves, the long one can down to the ground, The sleeve will be graded and hided while the angry mood is performed, and the sleeve will be dropped down to the ground while the sadness is displayed, the sleeve will be waved like a butterfly when the actor is happy; swinging sleeves quickly and straightly, brushing sleeves softly and manly, turning sleeves with various ways and throwing sleeves slowly and strongly.

- Putting sleeves on shoulder while crossing the bridge and water, putting sleeves on one's chest while saluting, pretending to cover one's eyes with the single sleeve while peeping, covering one's face with the single sleeve while sniggering, swinging up and down when showing the dragon head and phoenix tail, dancing like a lion rolling the ball, the good Chou actor will not reveal the hands or he/she will not be regarded as a good actor.

\section{C. "Shanzi" Proverb}

"Shanzi" Is a common prop. The ways of using fans in common operas are decided by the specific feature, age, status, profession and appearance of the figure (that is Shanzi Kongfu), such as "Wenxiong", "Wudu" means that Wensheng often put fans on their chest, while Wusheng often put fans in front of stomach. The formula for using fans is: on the stage, Laosheng hang fans down to their hips; Hualian put fans close to their faces; Xiaosheng swing fans before their sleeves; Emperors slap their fans before their chest.

However, there is no Sheng, Dan, Jing, Mo, and no more emperors, scholar and beauty in Tea-leaf Picking Opera. There are one Chou and two Dans in Tea-leaf Picking Opera, who always have the fans in their hands. Fans are very important in Tea-leaf Picking Opera, which run through Chuang, Zuo, Nian, Da, and Wu. It is not only the supporting point of figure but also is the important support of Tea-leaf Picking songs and dances. The most special point is that in Tea-leaf Picking Opera, "Sanzi" is "universal props":

- Replacing pigtails when driving cattle, replacing boat tracker when taking ship, replacing flower hoop when embroidering, replacing cone trip when stitching shoes, taking as straw hat in sunshine day, taking as umbrella in rainy day, taking as handle when pushing vehicle, putting fans on shoulders when carrying the sedan chair, putting fans in fields when planting the seedlings, taking fans as sickle when harvesting rice.

- Using as tea basket when picking tea, using as tea plate when drinking tea, using as knife when cutting vegetables, using as spatula when making dishes, using as musket when hunting birds and using as fishing rob when catching frog.

There are many kinds of "Shanzi" on the opera stage, such as folding fan, moon-shaped fan, feather fan, palm fan; palm-leaf fan etc., while there is only one type of fan in Tealeaf Picking Opera, "colored fan". In the performance of Tea-leaf Picking Opera, "Fan flower", "Fan dance" take much place. The predecessor are very strict about "Sanzi Kongfu", taking it as an important standard to measure the skills of an actor, therefore, there is a "formula" used by senior artistic to guide the apprentices to practice Sanzi Kongfu:

- If one wants to learn to be proficient, one must practice Shanzi Kongfu, putting fans away when reading the spoken parts, completely opening the fan when dancing, covering faces with fans when there is dust, shaking fans to get cool breeze, throwing fans in hands when especially happy, putting fans in hand when feeling sad, carrying fans on back when looking down, building a pergola with fans while looking out, 
making fans fly up and down like a butterfly and wave like a tornado, and there will be no good result of art if the Shanzi Kongfu is not good.

- Using fan without seeing it, taking fan just like there is no fan, old Chou flaps beard with fan, young Chou flaps chest with fan, Dan flaps hair near ear with fan, matchmaker flaps hips with fan.

The "Sanzi" matching style of Tea-leaf Picking Opera, "Buzi", "Xiuzi", "Shanzi", forms a whole set of situated actions with rules. The organic combination of dancing actions of "Sanzi" has laid the artistic characteristics of Tealeaf Picking Opera, and is the perfect performing style of it, which are the specialty and value of Tea-leaf Picking Opera that is different from other operas. Putting sham to truth, taking virtuality to reality, and using form to display expression in Tea-leaf Picking Opera are used to highlight the essence of artistic conception in virtual space, it is not easy to write and play this opera well without these items.

\section{THE DEVELOPMENT AND EXISTENCE CRISIS OF HAKKA TEA-LEAF PICKING OPERA IN NORTHERN GUANGDONG}

\section{A. The Developmeng of Hakka Tea-leaf Picking Opera in Northern Guangdong}

On May 20, 2006, Tea-leaf Picking Opera in northern Guangdong was listed as the intangible cultural heritage of the first batch approved by the State Council. The author's project team members went to Shaoguan downtown, Wongyuan, Nanxiong, etc. to investigate the tea operas, and knew that the local governments and party organization took the development of Tea-leaf Picking Opera as an important affair of constructing the culture and socialist spiritual civilization, which built a good political environment for the existence and development of Tea-leaf Picking Opera.

In addition, Wang Shaoming mentioned that the government has invested a lot of human and material resources and financial resources when Tea-leaf Picking Opera is facing difficulties. In fact, in order to overcome the talent crisis, the Municipal Bureau of Culture and Tea-leaf Picking Opera Theatre did take the way of first investment, but the reality is that the policy support and financial support given by the government and all sectors of society are far from to maintain the continuity of talent training, and far from to build a virtuous circle for the cultivation of talents of Tea-leaf Picking Opera. The strength of government support is not continuous, and the results are bound to be poor.

\section{B. Existance Crisis of Hakka Tea-leaf Picking Opera in Northern Guangdong}

In the past more than ten years, Hakka Tea-leaf Picking Opera in northern Guangdong has won a lot of awards in music creation and performance. Like other national traditional arts, the traditional art of Tea-leaf Picking Opera also faces the inheritance dilemma of talent shortage and market shrinkage. Although from the perspective of political conditions, this opera has received the full support of the government, creating a good political ecological environment for the existence and development of Tea-leaf Picking Opera. In general, under the impact of the market tide, Tea-leaf Picking Opera falls into the paradox of development. In terms of the development of Tea-leaf Picking Opera Theater, it faces a shortage of talents and a shrinking market. The first is the lack of creative talents. According to the investigation, there are less than 30 people engaged in the compilation and research of Tea-leaf Picking Opera in Shaoguan at present, and even fewer of them are creators and excellent composers. According to the interview, there are very few and non-professional people who create Tea-leaf Picking Opera in each county of Shaoguan city. Most of the actors are middle-aged and elderly. No college students are willing to go to the mountainous areas to engage in this sluggish cultural cause.

Secondly, one of the reasons why the actors are out of touch is that they don't play a role the education industry. There are few young people who apply the drama major in this area. There is no Tea-leaf Picking Opera major in many colleges and universities. Because there is no systematic training, it mainly depends on the Chuan, Bang, Dai by the senior actors; the final impact is that the audience can hardly hear the real original singing of Tea-leaf Picking Opera.

Thirdly, the market is shrinking. Under the situation that postmodern music is popular all over the country and even the world, traditional art is also developing passively. At present, the equipment of Tea-leaf Picking Opera tends to be obsolete and out of date. Because the achievements of drama are slow, the interests are small, but the investment is very large, it is difficult to open a market.

\section{INHERITANCE STRATEGIES OF HAKKA TEA-LEAF PICKING OPERA IN NORTHERN GUANGDONG}

Based on the above development status of Hakka Tealeaf Picking Opera in northern Guangdong, several inheritance countermeasures have been put forward in this paper for reference to related departments by reading a large number of literature.

\section{A. Strengthening the Support of the Related Agencies}

1) Support from government: The support from the related government departments has always been a very strong guide to the cultural industry, many cultures have been developed again because of the strong support of the government agencies.

2) Support from education sector: The support of the education sector is the largest and practical part for the whole relevant support institutions. The education sector is the direct guider to schools and students, and the schools should carry out the necessary training on Hakka Tea-leaf Picking Opera to teenagers and normal university students.

3) Support from experts and scholars: The government set up the relevant researching institutions to organize the experts and scholars in the field of Hakka Tea-leaf Picking Opera in northern Guangdong to conduct in-depth academic and theoretical research, and to collect, sort, record, save and publish the document on this opera. 
extremely high artistic value. The survey found that as a intangible cultural heritage project, the Tea-leaf Picking Opera in northern Guangdong currently faces crises such as lack of talents, shrinking markets, insufficient government support, and insufficient social attention, and it is still difficult to survive. Based on this, this article proposes three system improvement strategies such as increasing the support of government cultural institutions, integrating core forces including art colleges and universities, and actively developing peripheral cultural industry clusters. It is hoped that it will help promote the ecological development of Tealeaf Picking Opera in northern Guangdong.

\section{REFERENCES}

[1] Xue Qing. Where Are You Going in Future, Tea-leaf Picking OperaThinking on the Existence and Future Development of Tea-leaf Picking Opera. Shanghai Theatre, Aug., 2007. (in Chinese)

[2] Wang Shaoming. Subsistence and Development of Tea-leaf Picking Opera under the Post-modernism Contect — Taking Tea-leaf Picking Opera as an Example [J]. Journal of Guangdong Education Institute, Feb.,2005. (in Chinese)

[3] Wang Qunying, Cao Guangtao. Artistic Features, Ecological Environment and Development Trend of Tea-leaf Picking Opera in northern Guangdong [J]. Drama Literature, 2012.02. (in Chinese)

[4] Hu Zhenbang, Cao Guangtao. Art Context and Inheritance of Folk Opera [J]. Shanghai Drama, 2015.05. (in Chinese) power of variety entertainment program in northern Guangdong, one the other hand, it improves the popularity of Tea-leaf Picking Opera in northern Guangdong.

3) Carrying out digital inheritance: If the local Tea-leaf Picking Opera can be made into a micro film belongs to Hakka people in northern Guangdong, this opera can be promoted to a certain extent and seek a new way of development. In this way, it will play a subtle role in promoting the culture of Tea-leaf Picking Opera and integrating it into the daily life of ordinary people.

\section{Actively Developing the Peripheral Cultural Industry Cluster}

1) Organizing and carrying out the relevant activities to integrate Tea-leaf Picking Opera in northern Guangdong into cultural tourism and exhibition industry: On one hand, it breaks the traditional and conservative performance form of Tea-leaf Picking Opera, on the other hand, it turns intangible cultural resources into mobile and innovative tourism cultural resources.

2) Organizing forces to infiltrate the music resources of Tea-leaf Picking Opera in northern Guangdong into internet: Nowadays, internet is an infinite potential new field, the music of Tea-leaf Picking Opera is not limited in words information, but also includes music scores, pictures, audio frequency and video frequency etc., which needs continuous hard exploration and collection of experts and scholars.

\section{CONCLUSION}

The Tea-leaf Picking Opera in northern Guangdong has formed a cultural brand with "Sanzi" as its artistic characteristics through long-term artistic practice, which has 